\title{
Are reproductive traits related to pollen limitation in plants? A case study from a Central European meadow
}

\author{
Michael Bartoš ${ }^{1}$, Štepán Janeček ${ }^{2}$, Petra Janeckova ${ }^{3}$, Eliška Padyšáková ${ }^{4}$, Robert Tropek ${ }^{5}$, \\ Lars Gotzenberger ${ }^{1}$, Yannick Klomberg ${ }^{2}$, and Jana Jersáková ${ }^{6}$ \\ ${ }^{1}$ Institute of Botany Czech Academy of Sciences \\ ${ }^{2}$ Charles University \\ ${ }^{3}$ Charles University Faculty of Science \\ ${ }^{4}$ Biology Centre, Institute of Enthomology, Czech Academy of Sciences \\ ${ }^{5}$ Affiliation not available \\ ${ }^{6}$ University of South Bohemia, Faculty of Science
}

April 28, 2020

\begin{abstract}
The deficiency of pollen grains for ovule fertilization can be the main factor limiting plant reproduction and fitness. Due to ongoing global changes, such as biodiversity loss and landscape fragmentation, a better knowledge of the prevalence and predictability of pollen limitation is challenging within current ecological research. In our study we used pollen supplementation to evaluate pollen limitation (at the level of seed number and weight) in 22 plant species growing in a wet semi-natural meadow. We investigated the correlation between the Pollen Limitation index (PL) and floral traits associated with plant reproduction or pollinator foraging behaviour. We recorded significant pollen limitation for approximately $41 \%$ of species (9 out of 22 surveyed). Seven species had a significant positive response in seed production and two species increased in seed weight after pollen supplementation. Considering traits, PL significantly decreased with the number of pollinator functional groups. The relationship of PL with other examined traits was not supported by our results. The causes of pollen limitation may vary among species with regard to 1) different reproductive strategies and life history, and/or 2) temporary changes in influence of biotic and abiotic factors at a site.
\end{abstract}

\section{Introduction}

Pollen limitation (i.e. limitation of seed production by deposition of pollen grains) belongs among the key factors affecting the fitness of individual plants and consequently, population dynamics and species survival (Ashman et al. 2004). Therefore, with the global pollination crisis (Potts et al. 2010, Burkle et al. 2013), pollen limitation has become a key topic of ecology and conservation of plant communities (e.g. Alonso et al. 2010, Castro et al. 2015, Janečková et al. 2019). Despite several decades of research, there is still no consensus on how widespread pollen limitation is in plant communities. The optimality theory (Haig and Westoby 1988) and sexual selection theory (Charnov 1982, but see Wilson et al. 1994) predict that pollen limitation should be rare. However, numerous empirical studies showed pollen limitation as a relatively common phenomenon (Burd 1994, Larson and Barrett 2000). A review of 306 plant species found evidence of pollen limitation (within an individual site) in $73 \%$ of the studies (Knight et al. 2005). Consequently, this suggested insufficient pollen receipt to be the major cause of reduced fruit production (Knight et al. 2005). Nevertheless, the existing geographical bias of available detailed data (Bennett et al. 2018) limit any strong generalisations on the extent of pollen limitation, as well as causes and consequences in individual plant species and in communities. 
Pollen supplementation experiments represent a standard method for pollen limitation quantification (Knight et al. 2006). Based on saturation by manually applied additional pollen to flowers, it allows a robust subsequent comparison of their fruit sets and/or seed sets with naturally pollinated flowers (Knight et al. 2006). Besides the effects of pollen saturation on the quantitative characteristics, possible trade-offs in resource allocation can be evaluated also by a qualitative comparison of seed or fruit sets (e.g. by their size or weight, Huang et al. 2017). Nevertheless, published results from pollen supplementation experiments are predominantly based on single-species case studies. Therefore, they may not be representative of the realized pollen limitation in communities (Vamosi et al. 2006). Plant species, as well as individuals in the population, may not be equally sensitive to changes in environmental and associated biotic conditions because the possible lack of pollination depends on the ecological context, plant life history, and type of breeding system (Ashman et al. 2004).

The shift of plant species to outcrossing can be caused by specific plant trait evolution regardless of the possible consequence of pollen limitation (Knight et al. 2005). However, the correlation of pollen limitation with various life-history and ecological traits was tested in only a few comparative studies (Larson and Barrett 2000, Garcia-Camacho and Totland 2009). In 224 species from 64 families of flowering plants, Larson and Barrett (2000) revealed pollen limitation as less intense in species which are self-compatible, autogamous, monocarpic, herbaceous, nectariferous, and occurring in open habitats and temperate regions. Although selfincompatible plants are generally expected to be more pollen limited than self-compatible plants (Burd 1994), this assumption may not always be true (Garcia-Camacho and Totland 2009). Furthermore, comparisons of pollen limitation between phenotypically specialized and generalized flowers reported ambiguous results. Larson and Barrett (2000) found that species with specialized floral morphology and less accessible nectar did not differ from those with generalized morphology in the level of pollen limitation. Contrarily, Lazaro et al. (2015) recorded that species with specialized flowers were more pollen limited than those with generalized flowers. Therefore, individual floral traits can explain only a small part of variation in pollen limitation (Larson and Barrett 2000).

New insights into the variation of pollen limitation causes could be provided by exploration of correlative effects between multiple reproductive and functional traits and pollen. For example, even key traits like dichogamy or clonality have not been thoroughly explored in this context. While dichogamy level has been suggested as ensuring higher autonomous seed set in plants exposed to outcross pollen limitation (Brys et al. 2013), clonality may provide reproductive advantage for obligate outcrossing species that are in the higher risk of pollen limitation (Vallejo-Marin and O'Brien 2007).

In this study, we applied pollen supplementation to evaluate the level of pollen limitation in a community of flowering plant species in a wet meadow in a fragmented cultural landscape in Central Europe. Consequently, we correlated the pollen limitation with multiple functional traits of the plant species. We hypothesized that the degree of pollen limitation of plant species will be influenced by (i) a type of breeding system, (ii) floral traits important for pollinator attraction and foraging technique, and (iii) their degree of functional specialization on pollinators. We expected that plants visited by a broad spectrum of different insect functional groups (i.e. bees, flies, beetles, etc.) will be less pollen limited. We also predicted that the lower pollen limitation would occur in pollinator-attractive plants with abundant nectar rewards and/or more open flowers. Last but not least, we provided a comprehensive pollen limitation dataset from Central Europe, a region previously largely neglected in pollination networks and pollen limitation studies (Bennett et al. 2018).

\section{Materials and methods}

\subsection{Study site}

Our focal plant community was situated in a semi-natural wet meadow near the Chobotovsky rybnik pond in the Landscape Protected Area of Železné hory (Bohemian-Moravian Highlands, Czech Republic; $535 \mathrm{~m}$ a.s.l., $\left.49^{\circ} 46^{\prime} 57^{\prime \prime} \mathrm{N}, 15^{\circ} 50^{\prime} 17^{\prime \prime} \mathrm{E}\right)$. We collected data on the 22 most abundant plant species flowering between the beginning of May and mid-July 2017. During the vegetation season, 51 insect-pollinated species were flowering. 


\subsection{Pollen limitation}

Supplemental hand-pollination was applied on randomly selected individuals (20-30 per species) with at least two open flowers in similar phenological phases. One flower was supplemented by conspecific pollen from plants minimally two meters apart to reduce the genetic closeness and the second was left to natural pollination as a control. Both hand-pollinated and control flowers were marked by coloured cotton yarn loosely knotted under the flowers. In species producing just a single flower (Anemone nemorosa) or compact inflorescences (Bistorta major ) on a single shoot, we applied the treatments on two neighbouring individuals. In Asteraceae species (Crepis paludosa and Tephroseris crispa) the treatments were applied on two whole capitula, and in Apiaceae species with compound umbels (Aegopodium podagraria and Chaerophyllum aromaticum ) the treatments were applied on two umbellets from two different umbels. All species with flowers in compact and sequentially opening inflorescences (i.e. Aegopodium podagraria, Bistorta major ,Chaerophyllum aromaticum, Crepis paludosa and Tephroseris crispa) were hand-pollinated repeatedly for several consecutive days throughout the whole flowering period. After the marked flowers wilted, their maturing ovaries were enclosed in fine nylon mesh bags to avoid any seed loss. We counted all viable seeds from the collected flowers or inflorescences and measured mean weight per seed. Because Dactylorhiza majalis produced numerous very small seeds, we used the capsule weight as a proxy for the number of developed seeds.

\subsection{Plants traits}

We collated information on seven plant characteristics: type of breeding system (i.e. extent of self-compatibility and autonomous selfing), level of dichogamy, clonality, amount of nectar reward, number of open flowers, and plant specialization on pollinator functional groups. Data on the extent of self-compatibility and autonomous selfing for 18 of the target species were obtained from our greenhouse pollination experiment (Bartoš et al. 2020). Data on dichogamy were extracted from the Biolflor database (Klotz et al. 2002) and transformed from the original seven categories to a continuous variable ranging from 0 to 0.5 , with the value 0.5 denoting an absence of dichogamy (i.e. simultaneous presence of male and female organs). The missing data on breeding type (four cases) and level of dichogamy (two cases) were replaced by average values from the whole dataset. The clonal multiplication (i.e. number of vegetative offspring per maternal shoot per year) was extracted from the Clo-Pla database (Klimešová et al. 2017). The daily sugar production in nectar reward was determined in the field for 15 flowers per plant species. Flowers from different plant specimens were bagged at their full anthesis for 24 hours after which nectar was extracted. Nectar was washed with distilled water using a $100 \mathrm{\mu l}$ Hamilton syringe and stored in a refrigerator prior to freezing, following Morrant et al. (2008). The amount of nectar sugars was quantified by high-performance liquid chromatography (HPLC) using the ICS-3000 system (Dionex), with an electrochemical detector and CarboPac PA 1 column. The nectar production was expressed in milligrams of nectar sugars per flower/day. Mean number of open flowers per species was calculated from 60 specimens per species from three meadows in the study region.

Plant functional specialization was expressed as the number of pollinator functional groups that touched anthers and/or stigmas during foraging. The pollinator spectrum for each plant species was counted from videos recorded in the field using portable video systems of VIVOTEK (IB8367-T) and MILESIGHT (MSC2962-FPB-IR60m) cameras. In total, 72 hours (equally covering day and night) per plant species were recorded in three different localities in the vicinity of the study area. All pollinators were split into eleven functional groups: ants, beetles, bumblebees, butterflies, honeybees, hoverflies, long-tonged flies, moths, other bees, other flies, and other hymenopterans. Groups which were represented by fewer than 3 visitors per plant species were excluded from the analyses, to avoid random visits.

\subsection{Data analysis}

Differences in reproductive success between supplemental hand-pollination and natural pollination at community and species levels were tested for both seed production and seed weight. Because the data contained many zero values and even after transformation did not meet the normality assumption, we applied nonparametric tests. At community level we used permutational MANOVA with permutation of residuals under 
a reduced model, where treatment served as fixed and plant species as random factor. At species level we used a one-sided test in non-parametric permutational ANOVA. Both tests were done within the PERMANOVA package in Primer 6 software (Anderson et al. 2008).

We calculated the Pollen Limitation index $(\mathrm{PL})$ as $\mathrm{PL}=\left(\mathrm{P}_{\mathrm{s}}-\mathrm{P}_{\mathrm{o}}\right) / \mathrm{P}_{\max }\left[\mathrm{P}_{\mathrm{s}}\right.$ or $\left.\mathrm{P}_{\mathrm{o}}\right]$ (Baskin and Baskin 2018), where $\mathrm{P}_{\mathrm{s}}$ is the number of seeds from pollen-supplemented flowers, $\mathrm{P}_{\mathrm{o}}$ is the number of seeds from openpollinated flowers and $\mathrm{P}_{\max }$ is the larger of the two values $\left(\mathrm{P}_{\mathrm{s}}\right.$ or $\left.\mathrm{P}_{\mathrm{o}}\right)$. For all subsequent analyses, similarly to Larson and Barrett (2000), we established zero as the lower boundary of the PL, because any negative indices likely resulted from a potential experimental error (Young and Young 1992), and therefore are not meaningful in the context of our study.

Although most studies assumed a linear relationship between possible plant seed set and traits, some studies predicted numerous relationships between plant and visitors to be non-linear (Morris et al. 2010, Thomson 2019). Thus, all correlations of PL with plant characteristics were tested using both simple and multiple linear as well as unimodal regressions. Because of right-skewed distribution, the values for nectar production and number of flowers were log-transformed prior to analysis. For selection of the best model we used AIC stepwise selection. All analyses, unless otherwise specified, were conducted using R (R Core Team 2019).

\section{Results}

\subsection{Seed production and seed weight}

The differences in both seed production and seed weight between pollen-supplemented and naturally pollinated flowers at the community level were statistically significant (permutational MANOVA; Pseudo- $\mathrm{F}=3.99$, $\mathrm{p}=0.023$, and Pseudo- $\mathrm{F}=6.92, \mathrm{p}=0.005$, respectively). At the species level, we found a statistically significant positive increase in seed production after pollen supplementation in seven species (i.e. Table 1): Anemone nemorosa, Lysimachia vulgaris, Lychnis flos-cuculi , Potentilla palustris ,Aegopodium podagraria , Ranunculus auricomus, andStellaria graminea. The mean weight per seed of the pollen-supplemented flowers was significantly higher in two species,Lychnis flos-cuculi and Cardamine pratensis. The capsula weight after the pollen supplementation significantly increased inDactylorhiza majalis . PLs for all individual species are presented in Fig.1.

\subsection{Traits correlations}

Our tests revealed that PL was significantly related only to the number of pollinator functional groups (Table 2, Fig.2). We found no significant relationship between PL and other tested traits, including the multiple regression with all traits $(\mathrm{F}=0.83, \mathrm{p}=0.57)$. The only trait selected by the AIC-based stepwise selection was again the plant specialization. All correlation indices between particular quantitative floral traits are presented (Table 1, Appendix A).

Both models, the unimodal and the linear, were significant (unimodal: $\mathrm{F}=7.95, \mathrm{p}=0.003$, Fig.2B; linear: $\mathrm{F}=4.39, \mathrm{p}=0.049$, Fig.2A). However, due to the relatively small number of target plant species, this unimodal relationship may be greatly affected by outlying values at the edges.

\section{Discussion}

Pollen limitation is generally considered a common phenomenon and many comparative studies report relatively high occurrence (62-73\%) in various habitats (Burd 1994, Ashman et al. 2004). However, we only recorded significant pollen limitation for approximately $41 \%$ of species (9 out of 22 surveyed) in our wet meadow community. Our findings are in concordance with a similar unusually low occurrence of pollen limitation in a temperate grassland community in western Norway (Hegland and Totland 2008). This study focused on pollen limitation and its relationship to plant species visitation rates and specialisation levels and revealed only two out of eleven $(\sim 18 \%)$ studied plant species to be significantly pollen limited. Moreover, Bennett et al. (2018) even documented no pollen limitation in investigated study of nine species in a Romanian meadow community. It might seem that the low levels of pollen limitation revealed in the pollen supplementation experiments are in agreement with the assumptions from the model by Haig and 
Westoby (1988), which stipulates that seed set in flowering plants should be equally limited by both pollen and resource availability. It further suggests that pollen supplementation should not increase seed set in populations at their evolutionary equilibrium, because resources should be unavailable for maturation of their additional fertilized ovules. However, Burd (2008) adjusted this model for stochastic variation in both ovule fertilization and resource availability, which made the model broadly in accordance with the recent meta-analysis (Burd 1994, Ashman et al. 2004), in which pollen limitation is found in most surveyed species.

The reported inconsistencies in the magnitude of pollen limitation could stem from several non-mutually exclusive reasons:

(1) Effect of sampling size and experimental design. Using power tests (via simulation) for pollen supplementation experiments, Thomson (2001) illustrated that moderate pollination deficits of up to $15 \%$ will usually not be detected with sample sizes of 20 individuals, and even 40 are insufficient for minor deficits. But, unfortunately, lower sampling effort (such as 20-30 individuals in our study) is an inevitable result of various logistic constrains and trade-offs between the data quantity and quality in most community studies (Hegland and Totland 2008, Wolowski et al. 2013, Lázaro et al. 2015, Bennett et al. 2018).

(2) Publication bias . The community approach, where multiple plant species are studied simultaneously, may lead to a better understanding of patterns in pollen limitation. It is because environmental characteristics, such as nutrient levels within a given community, are relatively homogenous in such studies and the role of plant traits in pollen limitation can, therefore, be better assessed. Nevertheless, there have been few studies focused on the relationships between plant traits and pollen limitation across whole communities (Motten 1986, Hegland and Totland 2008, González and Pérez 2010, Wolowski et al. 2013, Lázaro et al. 2015). All these studies recorded lower levels of pollen limitation in natural systems compared to the pollen limitation documented in comprehensive reviews that are mostly based on single-species studies (Burd 1994, Ashman et al. 2004). Therefore, the publication bias, favouring statistically significant responses which then become available for further studies, together with the omission of 'grey literature' and studies not written in English (Auger 2017), complicates our understanding of pollen limitation (Knight et al. 2006).

(3) Effect of pollinator abundance. Hegland and Totland (2008) discussed their results of low pollen limitation in the context of a possible higher pollinator abundance in the studied community, which could substantially reduce the quantitative pollen limitation. A partial cause of low pollen limitation in our study could be that the targeted semi-natural locality is situated in a relatively well-preserved and mosaic-like landscape with a limited influence of intensive agriculture. Such semi-natural, diverse, and heterogeneous environments support pollination services (Steffan-Dewenter and Westphal 2008, Viana et al. 2012) and thus increase the plant reproductive success, as suggested by Bennett et al. (2018) in their Romanian meadow community.

(4) Effect of plant community composition and study species selection. In our investigated community, only a few plant species with morphologically highly specialized flowers, which are expected to be more prone to pollen limitation, were present. Therefore, this community may have a lower pollen limitation than communities with a greater proportion of specialized flowers.

(5) Choice of the pollen limitation measure. An important factor determining the recorded magnitude of pollen limitation may also be the choice of its measure. Knight et al. (2006) compared 263 studies working with different measurements of the production component of reproduction and revealed the largest effect for relative fruit set, and the lowest effect for production of seeds/flower and seeds/fruit. However, because the magnitude of pollen limitation was inter-correlated among these response variables, Knight et al. (2006) assumed that pollen limitation occurs simultaneously at different stages of the plant reproduction, but with varying intensity. Also in our study the numbers of pollen-limited species varied substantially between the two applied measures, seed production and seed mass. Furthermore, Hegland and Totland (2008) pointed out that the two main components of plant reproductive success, seed production and seed mass, are often not included in the same studies.

In our studied community, two species showed significant positive seed weight response after pollen supplementation, though we expected the negative relationship. Several studies demonstrated that seed mass 
decreases with pollen availability due to seed size-number trade-off (Ashman et al. 2004). For example, Agren et al. (2006) recorded reduced mean seed size in hand-supplemented Primula farinosa by about 12\%, but a larger total mass of seeds than in naturally-pollinated plants. The opposite effect, i.e. increased seed weight after pollen supplementation could be explained by the increased pollen quality (Hegland and Totland 2008). Aizen and Harder (2007) suggested that the cross-pollen used for supplementation may have higher quality than the mixture of self- and cross-pollen available under the natural pollination. It seems evident that the magnitude of pollen limitation is dependent on the treatment level, e.g. whether the experimental design is applied only on a fraction of the plant's flowers or on the whole plant (Zimmerman and Pyke 1988). Unfortunately, because we treated only flower pairs, we can only speculate on the proportion of resource allocation in our study (Wesselingh 2007). The low differences in the seed weight between the treatments could be caused by the ability of the plant to compensate for any possible higher cost of an additional seed production induced by the supplemental pollination in only one flower.

Despite analyses of several floral and life history traits connected to plant reproduction, we only found the significant relationship of PL to the number of pollinator functional groups. This finding is in accordance with the meta-analysis of pollen limitation in different world regions (Vamosi 2006, Wolowski et al. 2014, Rodger and Ellis 2016), where the more pollinator-specialized plant species were also more pollen limited (but see Hegland and Totland 2008). However, Lazaro et al. (2015) pointed out that this relationship is not entirely clear and it is very important to distinguish between morphological (based on floral shape) and ecological (based on realized interactions) specialization. They found a strong negative relationship between pollen limitation and ecological generalization, but only for species with the morphologically specialized flowers. As a possible explanation they suggested that the morphologically specialized flowers benefit more from generalizing their pollination system in the lack of a primary pollinator (Lazaro et al. 2015). The high ecological generalization may however result in the stronger pollen limitation because of lower flower-visitor diversity with abundant low-efficiency pollinators transporting high loads of incompatible pollen (Gomez et al. 2010). Accordingly, we recorded stronger pollen limitation in the species with specialized, as well as highly generalized pollination systems. This supports the prediction that many mutual relationships between plants and visitors should be non-linear (Young 1988, Morris et al. 2010).

\section{Conclusions}

Our study recorded significant pollen limitation for approximately a third of species occurring in a wet meadow community. It was much lower than what has been reported in the previous reviews of single species studies, but higher when compared with all other community level studies. The discrepancy in the results of these studies can be attributed to several issues, such as sampling and publication biases. Except for the number of pollinator functional groups, we could not attribute pollen limitation to the other measured floral and life history traits. Therefore, some additional traits may also be contributing to patterns of pollen limitation. Such additional traits could be extrinsic traits (e.g. regional plant diversity) because interactions between extrinsic and floral or life history traits may be the major driver of pollen limitation in communities (Vamosi et al. 2013). Finally, other overlooked and possibly important factors can be spatial and temporal variations in pollen limitation within and among communities.

\section{Acknowledgments}

This work was supported by the Czech Science Foundation [GA CR 16-12243S and 20-16499S], Charles University [PRIMUS/17/SCI/8 and UNCE204069] and long-term research development project of the Czech Academy of Sciences [RVO 67985939]. We would like to thank Frederick Curtis Lubbe for English proofreading. We are grateful to Pavel Kratochvil, Jitka Kockova and Karolina Hruba for their help during the fieldwork.

\section{Appendix A. Supplementary data}

\section{Data accessibility statement}

Data supporting this manuscript will be made available on Dryad following acceptance. 


\section{References:}

Agren, J., Fortunel, C., Ehrlen, J., 2006. Selection on floral display in insect-pollinated Primula farinosa : effects of vegetation height and litter accumulation. Oecologia 150, 225-232.

Aizen, M. A., Harder, L. D., 2007. Expanding the limits of the pollen-limitation concept: effects of pollen quantity and quality. Ecology 88, 271-281.

Alonso, C., Vamosi, J. C., Knight, T. M., Steets, J. A., Ashman, T. L., 2010. Is reproduction of endemic plant species particularly pollen limited in biodiversity hotspots? Oikos 119, 1192-1200.

Anderson, M.J., Gorley, R.N., Clarke, K.R., 2008. PERMANOVA+ for PRIMER: guide to software and statistical methods. Plymouth, UK: PRIMER-E.

Ashman, T.-L., Knight, T. M., Steets, J. A., Amarasekare, P., Burd, M., Campbell, D. R., Dudash, M. R., Johnston, M. O., Mazer, S. J., Mitchell, R. J., Morgan, M. T., Wilson, W. G., 2004. Pollen limitation of plant reproduction: ecological and evolutionary causes and consequences. Ecology 85, 2408-2421.

Auger, P., 2017. Information sources in grey literature. Walter de Gruyter GmbH \& co KG.

Bartoš, M., Janeček, Š., Janečková, P., Padyšáková, E., Tropek, R., Götzenberger, L., Klomberg, Y., Jersáková, J., 2020. Self-compatibility and autonomous selfing of plants in meadow communities. Plant Biol. 22, 120-128.

Baskin, J. M., Baskin, C. C., 2018. Pollen limitation and its effect on seed germination. Seed Sci. Res. 28, 253-260.

Bennett, J. M., Thompson, A., Goia, I., Feldmann, R., Ştefan, V., Bogdan, A.,Rakosy, D.,Beloiu, M., Biro, I.-B., Bluemel, S., Filip, M., Madaj A.-M., Martin, A., Passonneau, S., Kalisch D.P., Scherer G., Knight T.M., 2018. A review of European studies on pollination networks and pollen limitation, and a case study designed to fill in a gap. AoB Plants 10, ply068.

Brys, R., Geens, B., Beeckman, T., Jacquemyn, H., 2013. Differences in dichogamy and herkogamy contribute to higher selfing in contrasting environments in the annual Blackstonia perfoliata (Gentianaceae). Ann. Bot. 111, 651-661.

Burd, M., 1994. Bateman's principle and plant reproduction: the role of pollen limitation in fruit and seed set. Bot. Rev. 60, 83-139.

Burd, M., 2008. The Haig-Westoby model revisited. Am. Nat. 171, 400-404.

Burkle, L. A., Marlin, J. C., Knight, T. M., 2013. Plant-pollinator interactions over 120 years: loss of species, co-occurrence, and function. Science 339, 1611-1615.

Castro, S., Dostálek, T., van der Meer, S., Oostermeijer, G., Münzbergová, Z., 2015. Does pollen limitation affect population growth of the endangered Dracocephalum austriacum L.? Popul. Ecol. 57, 105-116.

Charnov, E.L., 1982. The theory of sex allocation. Princeton University Press, Princeton, N.J.

García-Camacho, R., Totland, Ø., 2009. Pollen limitation in the alpine: a meta-analysis. Arct. Antarct. Alp. Res. 41, 103-111.

Gómez, J. M., Abdelaziz, M., Lorite, J., Jesús Muñoz-Pajares, A., Perfectti, F., 2010. Changes in pollinator fauna cause spatial variation in pollen limitation. J. Ecol. 98, 1243-1252.

Gonzalez, A. V., Perez, F., 2010. Pollen limitation and reproductive assurance in the flora of the coastal Atacama Desert. Int. J. Plant Sci. 171, 607-614.

Haig, D., Westoby, M., 1988. On limits to seed production. Am. Nat. 131, 757-759. 
Hegland, J. S., Totland, O., 2008. Is the magnitude of pollen limitation in a plant community affected by pollinator visitation and plant species specialisation levels? Oikos 117, 883-891.

Huang, Q., Burd, M., Fan, Z., 2017. Resource allocation and seed size selection in perennial plants under pollen limitation. Am. Nat. 190, 430-441.

Janečková, P., Janeček, Š., Bartoš, M., Hrázský, Z., 2019. Reproductive system of the critically endangered taxon Gentianella praecoxsubsp. bohemica . Preslia 91, 77-92.

Klimešová, J., Danihelka, J., Chrtek, J., de Bello, F., Herben, T., 2017. CLO-PLA: a database of clonal and bud bank traits of Central European flora. Ecology 98, 1179.

Klotz, S., Kühn, I., Durka, W., 2002. BIOFLOR-a database on biological and ecological traits of vascular plants in Germany. Schriftenreihe für Vegetationskunde 38, 1-334.

Knight, T. M., Steets, J. A., Ashman, T. L., 2006. A quantitative synthesis of pollen supplementation experiments highlights the contribution of resource reallocation to estimates of pollen limitation. Am. J. Bot. 93, 271-277.

Knight, T. M., Steets, J. A., Vamosi, J. C., Mazer, S. J., Burd, M., Campbell, D. R., Dudash, M. R., Johnston, M. O., Mitchell, R. J., Ashman, T. L., 2005. Pollen limitation of plant reproduction: Pattern and process. Annu. Rev. Ecol. Evol. S. 36, 467-497.

Larson, B. M., Barrett, S. C., 2000. A comparative analysis of pollen limitation in flowering plants. Biol. J. Linn. Soc. 69, 503-520.

Lázaro, A., Lundgren, R., Totland, Ø., 2015. Pollen limitation, species' floral traits and pollinator visitation: different relationships in contrasting communities. Oikos 124, 174-186.

Morris, W. F., Vázquez, D. P., Chacoff, N. P., 2010. Benefit and cost curves for typical pollination mutualisms. Ecology 91, 1276-1285.

Motten, A. F., 1986. Pollination ecology of the spring wildflower community of a temperate deciduous forest. Ecol. Monogr. 56, 21-42.

Potts, S. G., Biesmeijer, J. C., Kremen, C., Neumann, P., Schweiger, O., Kunin, W. E., 2010. Global pollinator declines: trends, impacts and drivers. Trends Ecol. Evol. 25, 345-353.

R Core Team, 2019. R: A language and environment for statistical computing. Vienna, Austria: R Foundation for Statistical Computing; Version 3.5.3

Rodger, J. G., Ellis, A. G., 2016. Distinct effects of pollinator dependence and self-incompatibility on pollen limitation in South African biodiversity hotspots. Biol. Lett. 12, 20160253.

Steffan-Dewenter, I., Westphal, C., 2008. The interplay of pollinator diversity, pollination services and landscape change. J. Appl. Ecol. 45, 737-741.

Thomson, J. D., 2001. Using pollination deficits to infer pollinator declines: Can theory guide us? Conserv. Ecol. 5 .

Thomson, D. M., 2019. Effects of long-term variation in pollinator abundance and diversity on reproduction of a generalist plant. J. Ecol. 107, 491-502.

Vallejo-Marin, M., O'Brien, H. E., 2007. Correlated evolution of self-incompatibility and clonal reproduction in Solanum(Solanaceae). New Phytol. 173, 415-421.

Vamosi, J. C., Knight, T. M., Steets, J. A., Mazer, S. J., Burd, M., Ashman, T. L., 2006. Pollination decays in biodiversity hotspots. Proc. Natl. Acad. Sci. USA 103, 956-961.

Vamosi, J. C., Steets, J. A., Ashman, T. L., 2013. Drivers of pollen limitation: macroecological interactions between breeding system, rarity, and diversity. Plant. Ecol. Divers. 6, 171-180. 
Viana, B. F., Boscolo, D., Mariano Neto, E., Lopes, L. E., Lopes, A. V., Ferreira, P. A., Pigozzo, C. M., Primo, L. M., 2012. How well do we understand landscape effects on pollinators and pollination services? J. Pollinat. Ecol. 7, 31-41.

Wesselingh, R. A., 2007. Pollen limitation meets resource allocation: towards a comprehensive methodology. New Phytol. 174, 26-37.

Wilson, P., Thomson, J.D., Stanton, M.L., Rigney, L.P., 1994. Beyond floral Batemania: gender biases in selection for pollination success. Am. Nat. 143, 283-296.

Wolowski, M., Ashman, T. L., Freitas, L., 2013. Community-wide assessment of pollen limitation in hummingbird-pollinated plants of a tropical montane rain forest. Ann. Bot. 112, 903-910.

Wolowski, M., Ashman, T. L., Freitas, L., 2014. Meta-analysis of pollen limitation reveals the relevance of pollination generalization in the Atlantic forest of Brazil. PLoS One , 9 (2), e89498.

Young, H. J., 1988. Differential importance of beetle species pollinating Dieffenbachia longispatha (Araceae). Ecology 69, 832-844.

Young, H. J., Young, T. P., 1992. Alternative outcomes of natural and experimental high pollen loads. Ecology 73, 639-647.

Zimmerman, M., Pyke, G. H., 1988. Reproduction in Polemonium : assessing the factors limiting seed set. Am. Nat. 131, 723-738.

Table 1. Seed production and seed weight for the supplementary hand-pollinated and naturally-pollinated flowers. Asterisks denote p-values of species with statistically significant one-sided test in non-parametric permutation ANOVA.

\begin{tabular}{|c|c|c|c|c|c|c|}
\hline & No. of seeds & No. of seeds & No. of seeds & No. of seeds & No. of seeds & No. o \\
\hline $\begin{array}{l}\text { Family } \\
\text { Species }\end{array}$ & $\begin{array}{l}\text { Control } \\
\text { mean }\end{array}$ & $\begin{array}{l}\text { Control } \\
\text { (std.dev) }\end{array}$ & $\begin{array}{l}\text { Supplemented } \\
\text { mean }\end{array}$ & $\begin{array}{l}\text { Supplemented } \\
\text { (std.dev) }\end{array}$ & $\begin{array}{l}\text { PERMANOVA } \\
\text { Pseudo F }\end{array}$ & $\begin{array}{l}\text { PERI } \\
\mathrm{p}\end{array}$ \\
\hline \multicolumn{7}{|l|}{ Apiaceae } \\
\hline Aegopodium podagraria & 16.76 & $( \pm 8.85)$ & 21.00 & $( \pm 8.91)$ & 3.75 & $0.040^{\circ}$ \\
\hline Chaerophyllum aromaticum & 20.63 & $( \pm 11.8)$ & 20.74 & $( \pm 9.3)$ & 0.00 & 0.479 \\
\hline Asteraceae & Asteraceae & & & & & \\
\hline Crepis paludosa & 30.07 & $( \pm 13.56)$ & 30.20 & $( \pm 10.77)$ & 0.00 & 0.487 \\
\hline Tephroseris crispa & 55.95 & $( \pm 30.02)$ & 52.60 & $( \pm 16.07)$ & 0.24 & 0.319 \\
\hline Boraginaceae & Boraginaceae & & & & & \\
\hline Myosotis palustris & 1.25 & $( \pm 1.22)$ & 1.83 & $( \pm 1.34)$ & 3.01 & 0.063 \\
\hline Brassicaceae & Brassicaceae & & & & & \\
\hline Cardamine amara & 9.72 & $( \pm 7.05)$ & 7.94 & $( \pm 7.53)$ & 0.68 & 0.208 \\
\hline Cardamine pratensis & 5.89 & $( \pm 5.2)$ & 8.11 & $( \pm 5.18)$ & 2.53 & 0.066 \\
\hline Caryophyllaceae & Caryophyllaceae & & & & & \\
\hline Lychnis flos-cuculi & 76.32 & $( \pm 55.12)$ & 100.68 & $( \pm 46.74)$ & 5.10 & 0.021 \\
\hline Stellaria graminea & 7.54 & $( \pm 6.00)$ & 9.57 & $( \pm 4.86)$ & 3.12 & $0.045^{\circ}$ \\
\hline Hypericaceae & Hypericaceae & & & & & \\
\hline Hypericum maculatum & 339.10 & $( \pm 142.53)$ & 364.45 & $( \pm 161.06)$ & 1.03 & 0.165 \\
\hline Lamiaceae & Lamiaceae & & & & & \\
\hline Ajuga reptans & 3.40 & $( \pm 1.12)$ & 3.13 & $( \pm 1.13)$ & 0.52 & 0.261 \\
\hline Orchidaceae & Orchidaceae & & & & & \\
\hline Dactylorhiza majalis & 0.01 & $( \pm 0.00)$ & 0.01 & $( \pm 0.01)$ & 10.15 & 0.001 \\
\hline Plantaginaceae & Plantaginaceae & & & & & \\
\hline Veronica chamaedrys & 2.00 & $( \pm 2.95)$ & 3.00 & $( \pm 3.42)$ & 0.68 & 0.208 \\
\hline Polygonaceae & Polygonaceae & & & & & \\
\hline
\end{tabular}




\begin{tabular}{|c|c|c|c|c|c|c|}
\hline & No. of seeds & No. of seeds & No. of seeds & No. of seeds & No. of seeds & No. o \\
\hline Bistorta major & 79.50 & $( \pm 45.13)$ & 69.85 & $( \pm 36.36)$ & 2.16 & 0.080 \\
\hline Primulaceae & Primulaceae & & & & & \\
\hline Lysimachia vulgaris & 12.65 & $( \pm 16.24)$ & 39.05 & $( \pm 36.66)$ & 9.29 & 0.003 \\
\hline Ranunculaceae & Ranunculaceae & & & & & \\
\hline Anemone nemorosa & 7.11 & $( \pm 4.69)$ & 11.61 & $( \pm 7.01)$ & 10.71 & 0.002 \\
\hline Caltha palustris & 30.82 & $( \pm 39.43)$ & 32.82 & $( \pm 27.1)$ & 0.03 & 0.429 \\
\hline Ranunculus acris & 19.33 & $( \pm 7.08)$ & 15.44 & $( \pm 8.12)$ & 3.43 & 0.041 \\
\hline Ranunculus auricomus & 10.40 & $( \pm 3.28)$ & 11.80 & $( \pm 2.91)$ & 3.64 & 0.041 \\
\hline Ranunculus flammula & 31.89 & $( \pm 16.94)$ & 37.83 & $( \pm 12.67)$ & 2.23 & 0.076 \\
\hline \multicolumn{7}{|l|}{ Rosaceae } \\
\hline Potentilla erecta & 5.55 & $( \pm 3.14)$ & 6.15 & $( \pm 3.34)$ & 0.56 & 0.238 \\
\hline Potentilla palustris & 219.11 & $( \pm 80.41)$ & 253.16 & $( \pm 54.14)$ & 4.05 & 0.029 \\
\hline
\end{tabular}

Table 2. - Linear regressions of selected traits with pollen limitation. Asterisks denote p-values of species with statistically significant test.

\begin{tabular}{llll}
\hline Traits & F-statistic & DF & p-value \\
\hline $\begin{array}{l}\text { Specialization (No. of } \\
\text { pollinator functional }\end{array}$ & 4.39 & 20 & $0.049^{*}$ \\
groups) & & \\
Clonality & 1.24 & 20 & 0.278 \\
Dichogamy & 0.30 & 20 & 0.586 \\
Sugar content & 1.29 & 20 & 0.268 \\
No. of open flowers & 0.66 & 20 & 0.426 \\
Self-compatibility & 0.70 & 20 & 0.411 \\
Autonomous selfing & 0.17 & 20 & 0.681 \\
\hline
\end{tabular}

Fig. 1. Pollen Limitation index (PL) with standard error for 22 plant species from a wet meadow community in Central Europe. Asterisks denote statistically significant values of PL in individual plant species.

Fig. 2. Linear (A) and polynomial (B) regression of pollen limitation index (PL) with plant specialization (number of functional groups of flower visitors). Dashed lines denote the $95 \%$ confidence interval for the model curve. Plant species (see complete list in Table 1) are presented as three letter abbreviations. 


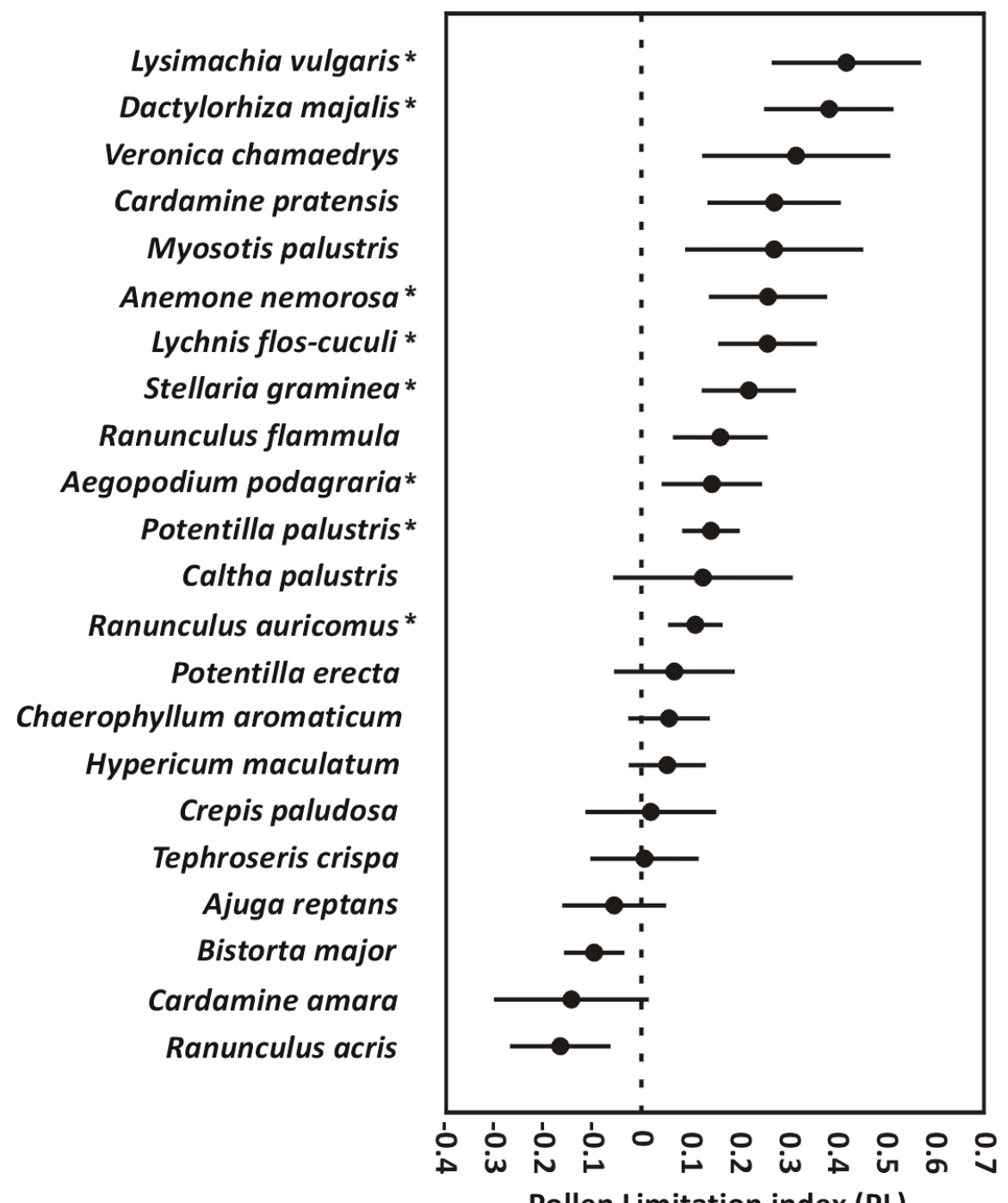

Pollen Limitation index (PL) 

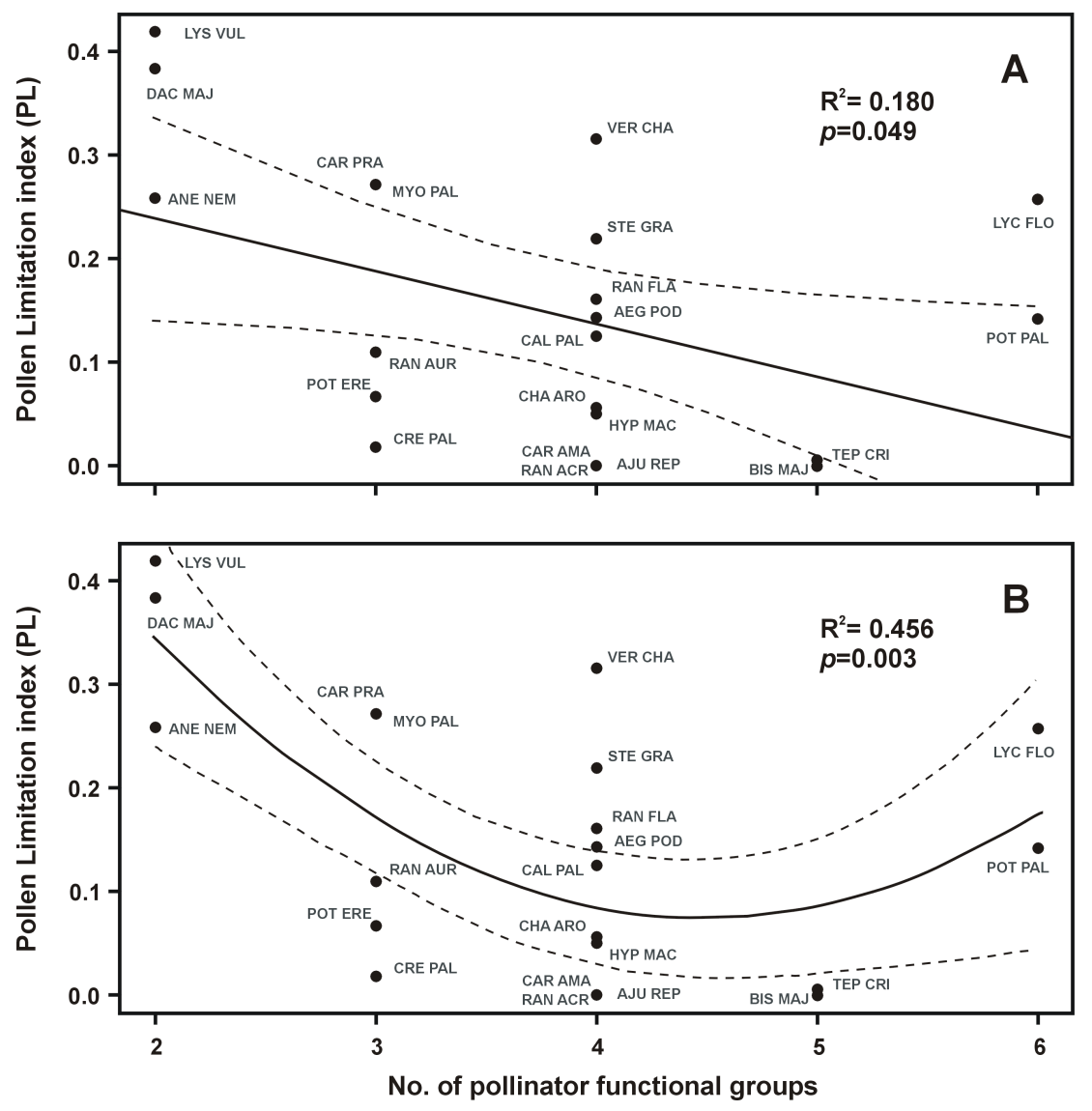